\title{
Investigando a prática pedagógica dos professores de ciências no município de Barra dos Coqueiros, SE: abordagem do tema manguezal
}

Investigating the pedagogical practice of science teachers in the Barra dos Coqueiros city, SE: the approach of the theme mangrove

\author{
A. Santos ${ }^{1 *} ;$ C. A.Vasconcelos ${ }^{1,2}$ \\ ${ }^{1}$ Programa de Pós-Graduação em Ensino de Ciências e Matemática/Universidade Federal de Sergipe 49100-000, São \\ Cristóvão-SERGIPE, Brasil. \\ ${ }^{2}$ Departamento de Educação da Federal de Sergipe 49100-000, São Cristóvão-SERGIPE, Brasil. \\ *aldeci26@hotmail.com
}

(Recebido em 06 de outubro de 2015; aceito em 03 de novembro de 2016)

\begin{abstract}
Este artigo objetivou investigar a prática pedagógica dos professores de ciências em escolas do município de Barra dos Coqueiros/SE, quanto à abordagem do tema manguezal. A metodologia foi baseada na aplicação de questionários para professores que ministram aulas de Ciências nas turmas do $6^{\circ}$ ano, de escolas das redes pública e particular, visando analisar de que forma o tema manguezal é abordado durante suas aulas de Ciências. Segundo os professores entrevistados, a principal fonte de referência utilizada continua sendo o livro didático. De acordo com os professores entrevistados, o livro didático não é o único recurso utilizado, tendo eles a preocupação de buscar outros recursos para o planejamento de suas aulas; além disso, a maioria relaciona os conteúdos ministrados em suas aulas ao que os alunos vivenciam no cotidiano.

Palavras-chave: Aulas de ciências, Prática pedagógica, Manguezal.
\end{abstract}

The said article aimed to investigate the pedagogical practice of science teachers in the Barra dos Coqueiros schools, SE, as the theme mangroves approach. The methodology was based in applying on questionnaires for teachers who teach science classes in classes of the 6th year, schools of public and private networks aiming to analyze in what way the theme mangrove issue is addressed during their science classes. Per the teachers interviewed, the main source of reference used still is the textbook; according to the interviewed teachers, the textbook is not the only resource used, having the same the concern to seek other resources for planning your classes; Moreover, most lists the contents taught in their classes the students experience in their daily lives.

Keywords: Lessons science, pedagogical practice, Mangrove.

\section{INTRODUÇÃO}

A educação existe em diversas sociedades, apesar de não haver forma única nem um único modelo para a mesma, podendo ser difusa. Mesmo em comunidades onde não há um sistema centralizado de governo, escolas e ensino especializado formal, a educação e a aprendizagem estão presentes.

Educação, do latim “educere”, significa extrair, tirar, desenvolver. Consiste na formação de caráter; é um processo vital, para o qual concorrem forças naturais e espirituais, conjugadas pela ação consciente do educador e pela vontade livre do educando (BRANDÃO, 1982) [1]. Segundo o filósofo Jacques Maritain (cit. in BRANDÃO, 1982, p. 65), “... o objetivo da educação é guiar o homem no desenvolvimento dinâmico, no curso do qual se constituirá como pessoa humana, dotada das armas do conhecimento, do poder de julgar e das virtudes morais".

De acordo com a atual Constituição Brasileira, a educação é um direito de todos os cidadãos; e a escola, como instituição social, está inserida numa certa realidade social que a influencia e na qual exerce influência de valores na ciência, na política e na cultura [2].

Diante do exposto, faz-se necessário que o Ensino de Ciências não seja distanciado da realidade vivida pelos alunos e nem baseado apenas na mera transmissão de informações, pois: 
A ciência pronta e acabada torna-se uma barreira a qualquer construção do conhecimento e contribui para uma atitude ingênua frente à ciência. Dessa forma, o conhecimento científico, construção sofisticada e gradual da mente humana, passa a ser tomado pelo aluno como algo passivel de mera assimilação e não como conhecimento elaborado. Essa visão deve ser abolida para que o estudante possa perceber-se como sujeito do processo educativo (MOURA; VALE 2001, p. 138) [3].

Até a promulgação da Lei de Diretrizes e Bases da Educação (LDB) n ${ }^{\circ} 4.024$ de 1961, o cenário escolar era dominado pelo ensino tradicional, no qual cabia ao professor a transmissão de conhecimentos acumulados, por meio de aulas expositivas, e aos alunos, a absorção dos conteúdos e reprodução das informações [4]. Em 1971, com a Lei 5.692, as aulas de Ciências Naturais deixaram de ser ministradas apenas nas duas séries do antigo curso ginasial, passando a ser de caráter obrigatório nas oito séries do $1^{\circ}$ grau [4]. Atualmente, a maioria dessas aulas de Ciências ainda continua baseada na mera transmissão de informações, tendo como principal recurso o livro didático e sua transcrição na lousa, tornando assim as aulas desinteressantes e pouco compreensíveis, fazendo com que os alunos sejam meros expectadores [5].

Diante dessa situação, Lopes (2001) [6] destaca que o professor deve ser criativo, de espírito transformador; deve sempre tentar inovar sua prática. Um dos caminhos para tal fim seria dinamizar as atividades desenvolvidas em sala de aula. O que se percebe em algumas salas de aula, porém, é a utilização única do livro didático, prevalecendo como principal instrumento de trabalho do professor em sua prática docente.

Uma das principais dificuldades enfrentadas pelos professores é a falta de materiais didáticos adequados à sua realidade, recursos que levem em consideração sua cultura e linguagem e que atendam às necessidades reais dos alunos. Os Parâmetros Curriculares Nacionais (PCN) trazem que o cotidiano e as relações estabelecidas com o ambiente físico e social devem permitir e dar significado a qualquer conteúdo curricular, fazendo a ponte entre o que se aprende na escola e o que se faz, vive e observa diariamente [7]. Sendo assim, a contextualização tem papel fundamental nesse processo, através de vínculos diretos entre o conhecimento disciplinar e a realidade do aluno, proporcionando uma aprendizagem significativa [8]. Ao contextualizar os conteúdos em sala de aula, surgem novas maneiras de o aluno enxergar a realidade e aplicar esse conhecimento ao seu cotidiano, interligando a abordagem feita pelo professor em sala de aula às informações trazidas pelos educandos, a partir de suas vivências. Apesar de a contextualização ser de fundamental importância na aprendizagem, esta, na maioria das vezes, não é trabalhada pelos docentes em suas aulas, pois, embora estejam sempre inovando sua pratica pedagógica, os métodos tradicionais ainda continuam sendo utilizados, tendo como principal material de suporte o livro didático. Segundo Franco (1982) [9], os livros didáticos se destinam a instruir, coadjuvando o trabalho do professor numa área qualquer do conhecimento humano, tendo como função apresentar conteúdo das matérias curriculares.

Segundo as orientações das Diretrizes de Ciências do Estado do Paraná, as estratégias de ensino e os recursos pedagógico-tecnológicos e instrucionais são fundamentais para a prática docente do professor de Ciências. Além disso, contribuem de forma significativa para melhorar as condições de aprendizagem aos estudantes [10]. Por isso, cabe ao professor selecionar e utilizar outros materiais e instrumentos mais atrativos para os alunos, como: livros paradidáticos, jogos, revistas, suplementos de jornais, vídeos, CD-ROM, entre outros, que estejam relacionados ao contexto vivido pelos alunos, a fim de que estes obtenham uma melhor aprendizagem sobre os temas mais próximos ao dia a dia.

Observando a realidade do Estado de Sergipe, especificamente o município de Barra dos Coqueiros, que apresenta áreas de manguezal, é indispensável a utilização de materiais didáticos contextualizados à realidade dos alunos. Outra finalidade dos materiais didáticos é suprir as deficiências encontradas nos livros didáticos e aulas de Ciências, acerca dos conteúdos referentes ao ecossistema local. Dessa forma observa-se que o manguezal, apesar de ocupar grande parte do litoral brasileiro, não tem sido abordado adequadamente pelos professores e pela maioria dos livros didáticos, que o fazem de maneira superficial, dissociada da realidade vivida pelos alunos. Este fato é comprovado através dos PCNs, nos quais se verifica que o manguezal é pouco enfatizado, 
ainda que neles se destaque a importância de desenvolver atividades práticas no ensino e produção de materiais didáticos sobre o tema (BRASIL, 1998). Desta forma, este trabalho tem como objetivo investigar a prática pedagógica dos professores de Ciências de $6^{\circ}$ ano do ensino fundamental em escolas do município de Barra dos Coqueiros-SE, ao abordar o tema "manguezais".

\section{MATERIAIS E MÉTODOS}

Para realização deste estudo buscou-se uma metodologia centrada na aplicação de questionários aos professores que ministram aulas de ciências nas turmas do $6^{\circ}$ ano, de escolas das redes pública e particular, localizadas na sede do município de Barra dos Coqueiros, no ano de 2013. Os questionários visaram analisar a prática pedagógica dos professores em sala de aula, constando perguntas como: Quais recursos os docentes utilizaram no desenvolvimento de suas aulas?, Contextualizam os assuntos abordados? e De que maneira utilizam o livro didático? Foi também solicitada a opinião deles a respeito dos conteúdos relacionados ao tema "manguezais". Vale ressaltar que as respostas dos professores foram transcritas no trabalho da mesma forma que foram escritas nas respostas aos questionários.

\section{RESULTADOS E DISCUSSÃO}

\subsection{Caracterização dos sujeitos}

Dentre os professores entrevistados, a maioria tem formação superior completa, sendo estes licenciados em Ciências Biológicas ou em Pedagogia. Apenas um professor, dentre os nove entrevistados, ainda estava concluindo o curso de Ciências Biológicas (Fig. 1). O fato de haver a presença de profissionais da área de Pedagogia lecionando a disciplina de Ciências chama a atenção, pelo fato de eles não terem habilitação adequada para o exercício da função.

De acordo com o artigo 62 da LDB (Lei de Diretrizes e Bases), $n^{\circ} 9.394$, de 20 de dezembro de 1996, os profissionais formados em Pedagogia são habilitados para atuar na educação infantil e nas quatro primeiras séries do ensino fundamental. A formação dos professores de Ciências entrevistados foi realizada em três instituições de ensino superior: Universidade Federal de Sergipe (UFS), Universidade Estadual Vale do Acaraú (UVA) e a Faculdade Pio X, todas no estado de Sergipe.

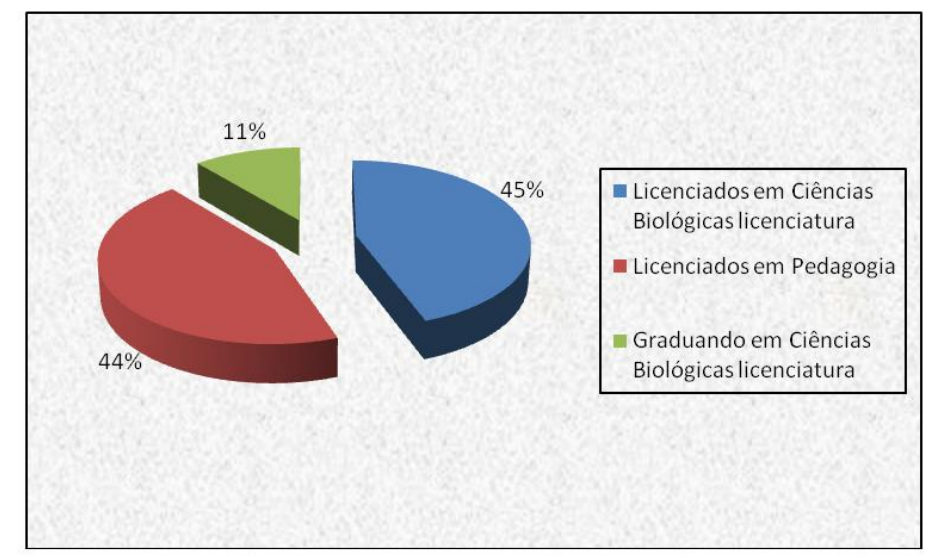

Figura 1: Formação dos professores de Ciências Fonte: Pesquisa de campo, 2013.

A maioria dos professores entrevistados concluíram sua graduação recentemente, e somente 13\% concluíram há mais de nove anos. Boa parte dos docentes (78\%) leciona em escolas públicas estaduais e municipais. Apenas $22 \%$ dos professores ministram suas aulas também em escolas particulares. 


\subsection{Análise dos questionários dos professores}

Todos os professores afirmaram que as escolas onde lecionam dispõem de recursos necessários para o desenvolvimento de suas aulas. Porém, mais de 50\% dos docentes afirmam que tal disponibilidade é apenas parcial, ou seja, refere-se a apenas alguns dos recursos. De alguma maneira, esse fator é positivo, pois, apesar de as escolas não oferecerem todos os recursos necessários, elas demonstram uma preocupação em oferecer algumas condições apropriadas para que o professor possa desenvolver melhor suas aulas.

Quando indagados sobre quais seriam os recursos utilizados no planejamento de suas aulas, os professores optaram por mais de um item, sendo os mais citados os livros didáticos, revistas, internet, vídeos e jornais (Fig. 2). Apesar de haver certo equilíbrio entre as respostas, o livro didático continua sendo o principal instrumento utilizado pelo professor no planejamento das aulas. Entretanto, o gráfico a seguir também demonstra que os professores não utilizam o livro como única ferramenta de pesquisa, e que se preocupam em procurar outras fontes que possam, além de complementar os livros didáticos, também fornecer outros recursos que venham a auxiliá-lo em sua prática pedagógica.

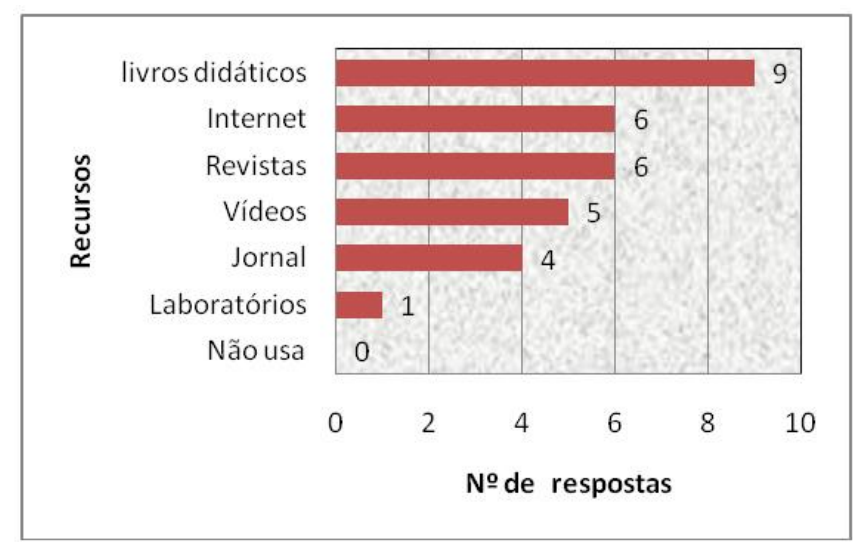

Figura 2: Recursos que utilizam no planejamento de suas aulas.

Fonte: Pesquisa de campo, 2013.

Quando perguntados com que frequência se utilizam do livro didático em suas aulas, os professores entrevistados nas escolas da sede do município de Barra dos Coqueiros foram unânimes em afirmar que fazem uso desse recurso diariamente. De acordo com Fracalanza e Neto (2006) [11], os livros didáticos ainda são comumente usados como fonte de texto, ilustrações e atividades.

Reforçando esta questão, Vasconcelos et al. (2007, p. 38) [12] propõem

uma discussão, talvez a mais controvertida, da questão do livro didático, que se constitui para o professor uma 'indispensável muleta que o apoia' e para o aluno numa das únicas possibilidades de contato com a língua escrita.

Dentre os livros mais utilizados pelos professores estão os de autores como Gowdak e Martins (2006), Cruz (2004) e Gewandsnajder (2004). Porém, alguns entrevistados vão além dos mencionados e buscam diversificação em outros materiais, a exemplo dos disponíveis na internet.

Diante desse resultado, percebe-se que os docentes buscam outras fontes de pesquisa para a complementação dos conteúdos em suas aulas, pois não estão satisfeitos com o livro que utilizam. Os professores da Educação Básica não estão utilizando fielmente os livros didáticos postos no mercado, na forma como idealizados e disseminados por autores e editoras, fazendo, assim, constantes modificações nos livros para tentar moldá-los à sua realidade escolar e às suas convicções pedagógicas [11].

As respostas dos professores quanto à questão de os livros didáticos atenderem ou não a suas necessidades foram as mais variadas (Fig. 3). Grande parte deles respondeu que tais livros utilizados deixam muito a desejar, apontando alguns fatores: "Os conteúdos são muito resumidos" (professora da rede particular de ensino); "Como a Ciência é dinâmica, você como profissional, tem que atualizar-se diariamente, por jornais, internet, cursos de atualização etc." (professora da 
rede pública de ensino). Segundo Krasilchik (2004) [13], a adoção de um livro requer uma cuidadosa análise de sua estrutura, do seu conteúdo e dos valores implícitos e explícitos que apresentam aos estudantes. Uma escolha malfeita acarreta prejuízos, no mínimo, para todo o ano letivo.

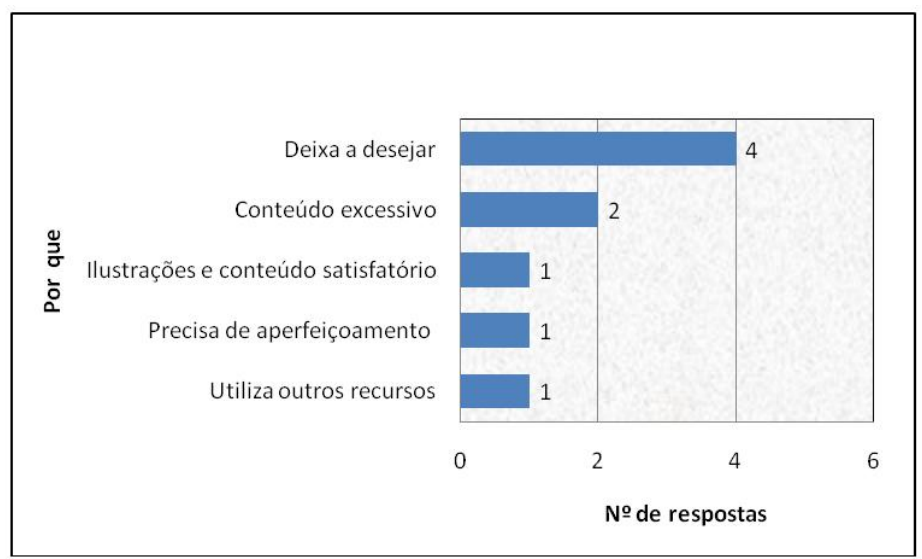

Figura 3: Justificativa dos professores de Ciências do $6^{\circ}$ ano entrevistados quanto ao fato de o livro suprir suas necessidades. Fonte: Pesquisa de campo, 2013.

Quanto à abordagem do tema manguezal nos livros didáticos, em torno de $50 \%$ dos entrevistados afirmaram que esse tema não é explorado adequadamente. Percebe-se que, ao menos na opinião desses docentes, que os autores dos livros utilizados e mencionados não fazem uma abordagem adequada acerca do ecossistema manguezal. Isto, de certa forma, é um fator negativo, pois vai influenciar diretamente na aprendizagem dos alunos, por se tratar de um ecossistema presente no litoral sergipano, além de fazer parte da realidade e vivência dos próprios alunos, no caso do município foco do estudo e de outras comunidades costeiras, que se utilizam desses materiais. Segundo Fracalanza e Neto (2006, p. 61) [12]: "Infelizmente, alguns livros trabalham o cotidiano de forma genérica, não levando em consideração as características de cada realidade em que o aluno e sua escola estão inseridos".

Boa parte dos professores disse trabalhar o tema em suas aulas. Esse fato pode ser considerado positivo, pois, atualmente, pelo fato de o professor ter uma carga horária de trabalho elevada, muitas vezes em mais de uma escola, quase não sobra tempo para preparar suas aulas. Além disso, fica evidente, a partir das respostas dos professores, a sua preocupação em utilizar exemplos de ecossistemas que fazem parte do contexto do aluno, a fim de que haja uma aprendizagem mais significativa dos conteúdos. De fato, para que a aprendizagem realmente aconteça, ela precisa ser significativa para o aluno, envolvendo-o como pessoa [14].

A maioria dos docentes afirmou que algumas vezes sente dificuldade em abordar o tema manguezal em sala de aula. Os que responderam não ter dificuldade alguma ao trabalhar o conteúdo talvez tenham algum conhecimento acerca do assunto, dando a ele segurança para discuti-lo em sala de aula.

Dos professores entrevistados, a maioria respondeu que tinha conhecimentos para ministrar aulas sobre o tema manguezal, sendo que $33 \%$ consideram seu conhecimento suficiente e $45 \%$ afirmaram que não tinham domínio suficiente para ministrar boas aulas. Estes $45 \%$ justificaram essa afirmação com respostas como: "Nunca estamos sabendo de tudo, há sempre coisas novas aparecendo e sendo descobertas" (professora da rede pública estadual de ensino); "Devo me aprofundar mais em tal tema, pois é muito amplo" (professora da rede pública municipal de ensino) e "Esse tema exige que haja uma ligação entre teoria e prática e vários fatores impossibilitam, às vezes, a prática, além disso, é pouco abordado nos livros didáticos" (professora da rede particular de ensino). Percebe-se, através destas respostas, o interesse desses professores em aprofundar mais seus conhecimentos acerca do assunto e sua preocupação em relacionar o conteúdo à prática, tornando, assim, a aprendizagem menos "conteudista" e mais participativa.

Há também uma preocupação quanto à abordagem do tema manguezal nos livros didáticos, pois este é considerado a principal fonte de consulta, tanto para o professor quanto para o aluno. Dos 
professores entrevistados, $33 \%$ admitem conhecer suficientemente o assunto sobre manguezais: "Tive oportunidade de realizar projetos sobre o assunto e recentemente li trabalhos que meus colegas de curso realizaram" (professora da rede pública municipal de ensino); "Tive uma boa formação na universidade sobre o tema referido" (professor da rede particular de ensino); "Além dos recortes de revistas e jornais, também utilizo a internet para saber sobre as questões ambientais do momento" (professora da rede pública estadual de ensino). Apenas $22 \%$ dos professores entrevistados não justificaram suas respostas acerca da pergunta.

Grande parte dos docentes respondeu que a realidade dos alunos é levada em consideração durante suas aulas. Percebe-se com isso que tais professores tentam buscar o conhecimento prévio do aluno, facilitando a construção do conhecimento.

Discutindo esta questão, Miras (2003, p 61) [15] diz:

A aprendizagem é tanto mais significativa quanto mais relações com sentido o aluno for capaz de estabelecer entre o que já conhece, seus conhecimentos prévios e o novo conteúdo que lhe é apresentado como objeto de aprendizagem.

As justificativas dos professores quanto à relação dos conteúdos com as situações do dia a dia do aluno foram bem diversificadas, como podemos observar nas seguintes respostas: "É bem mais fácil para eles entenderem coisas que eles vivenciam do que o que eles nunca viram"; "É abstrato demais." (professora da rede pública municipal de ensino); "A contextualização facilita a aprendizagem" (professor da rede particular de ensino); "A maioria dos conteúdos que ministro nas aulas, tento trazer para o cotidiano do aluno" (professora da rede particular de ensino).

Os depoimentos descrevem a preocupação dos professores em relacionar seus conteúdos em sala de aula com o que o aluno vivencia em seu cotidiano. Além disso, os docentes compreendem a necessidade de trabalhar os conteúdos que levem em consideração as ideias, crenças e valores dos educandos, auxiliando dessa forma sua aprendizagem.

Os professores de Ciências optaram por mais de um item quanto aos aspectos importantes que deveriam ser tratados sobre os manguezais em sala de aula. Percebe-se certo equilíbrio entre as respostas dos professores, sendo os assuntos mais destacados a "Importância dos manguezais", "Problemas ambientais" e "Preservação dos manguezais". Verifica-se, nas respostas dos professores, que estes demonstram uma preocupação ao abordar aspectos intimamente ligados à problemática ambiental acerca dos manguezais, a importância socioeconômica destes para as comunidades ribeirinhas, como também a maneira pela qual podemos preservar esse ecossistema. É de fundamental importância que o professor transmita esses conhecimentos para os alunos, a fim de que estes se conscientizem da importância dos manguezais, e para que mais tarde possam buscar soluções para os problemas ambientais existentes nesse ecossistema, como também venham a conhecer mais sobre os principais aspectos sócio-econômicos responsáveis pela geração de fonte de renda e alimento para as populações ribeirinhas. De fato, a falta de conhecimento sobre a importância desse ecossistema é um dos maiores entraves para sua preservação e conservação [16].

O grau de importância dos manguezais para os alunos de Barra dos Coqueiros foi considerado alto pela maioria dos professores entrevistados (Fig.4), tendo eles justificado da seguinte forma: "Muitas pessoas utilizam algumas espécies de animais para a alimentação e como fonte de renda" (professora da rede pública municipal de ensino); "É de grande importância, visto que faz parte do ecossistema da sua cidade, e muitos sobrevivem tirando o seu sustento" (professora da rede particular de ensino); "Por se tratar de um bioma da região" (professor da rede particular de ensino), e "Pois, a solidez da cidade depende inteiramente dos manguezais; quem mantém a cidade são os mangues" (professora da rede pública estadual de ensino).

As respostas dos professores confirmam que os alunos, além de demonstrarem interesse em conhecer melhor o ecossistema manguezal, percebem a importância dele, uma vez que é responsável por parte da economia do município, e também porque serve como fonte de alimento e subsistência para a população que ali reside. 


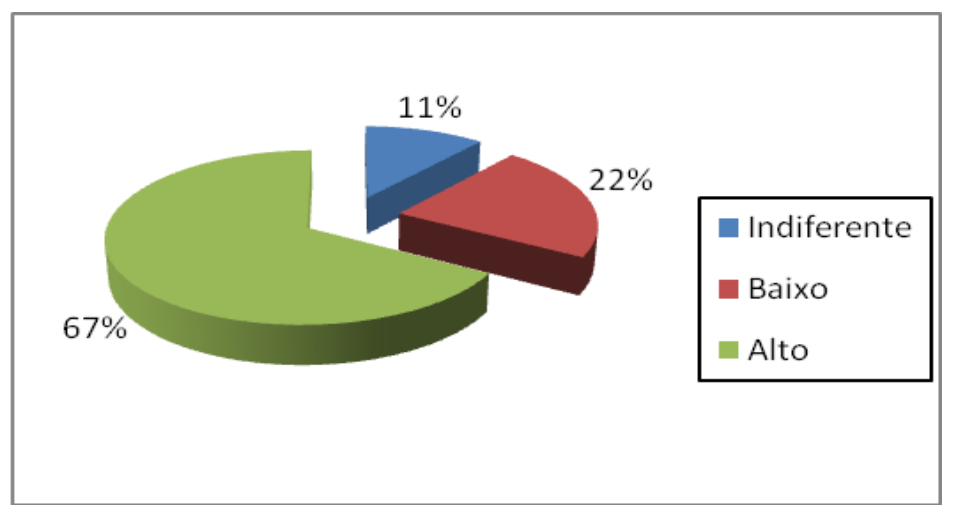

Figura 4: Distribuição percentual de respostas com relação à importância do manguezal para os alunos. Fonte: Pesquisa de campo, 2013.

\section{CONCLUSÕES}

Os resultados obtidos e discutidos ao longo do estudo/pesquisa expõem uma desvinculação entre a realidade discente e a prática pedagógica dos professores, percebendo-se assim um desestímulo diante das dificuldades do cotidiano escolar. Além disso, a falta de material didático-pedagógico, a desvalorização e o despreparo profissional são uma constante e os impedem de aproveitar a sua experiência de vida e trazê-la para sua prática pedagógica enquanto docentes. Dessa forma, após a execução do trabalho, foi possível verificar que a principal fonte de referência utilizada pelos professores continua sendo o livro didático, porém, os professores entrevistados, em grande parte, responderam que tais livros utilizados deixam muito a desejar. Além disso, segundo os docentes, o livro didático não é o único recurso utilizado, tendo eles a preocupação de buscar outros recursos para o planejamento de suas aulas. Por mais que sintam dificuldades em abordar o tema manguezal em suas aulas, os professores conseguem relacionar os conteúdos ministrados ao que os alunos vivenciam em seu cotidiano.

É importante ressaltar que, segundo os atores do estudo, os discentes sentem interesse em conhecer melhor o ecossistema manguezal. Isso se justifica pelo fato de os alunos perceberem a importância do ecossistema, uma vez que o manguezal é responsável por parte da economia do município e serve como fonte de alimento e subsistência para as pessoas que ali residem.

\section{REFERÊNCIAS BIBLIOGRÁFICAS}

1. Brandão C R. O que é educação. 6. Ed. São Paulo: Ática, 1982.

2. Rodrigues N. Da mistificação da escola à escola necessária. 2. ed. São Paulo, Cortez,1998.

3 Moura GRS, Vale JMF. O ensino de ciências na $5^{\mathrm{a}}$ e na $6^{\mathrm{a}}$ séries da escola fundamental. In Nardi R. (Org). Educação em ciências da pesquisa à prática docente. São Paulo. Escrituras Editora, 2001.

4 BRASIL, Secretaria de Educação Fundamental. Parâmetros curriculares nacionais: Ciências naturais. Terceiro e quarto ciclos. Brasília. MEC/SEF, 1998.

5 Delizoicov D, Angoti, JAP. Pernambuco MM. Ensino de ciências: fundamentos e métodos. 1. ed. São Paulo: Cortez,2003.

6 Lopes, AO. Aula expositiva: Superando o Tradicional. In VEIGA, I.P.A. (Org). Técnicas de Ensino: Por Que Não? 12 ed. Campinas: Papirus, 2001.

7 BRASIL, Secretaria da Educação Média e Tecnológica. Ciências da natureza, matemática e suas tecnologias: Parâmetros curriculares nacionais. Ensino médio. Brasília, MEC/SEMTEC, 2000.

8 Ramos MNA Contextualização no currículo de ensino médio: a necessidade da crítica na construção do saber científico. In: Revista do Ensino Médio. Brasília. v. 1, n. 3, p. 8, jan., 2003.

9 Franco ML. O livro didático de História no Brasil: a versão fabricada. São Paulo: Global, 1982.

10 PARANÁ. Secretaria de Estado da Educação. Diretrizes Curriculares de Ciências. Curitiba, 2008.

11 Fracalanza H, Neto JM.; (Orgs.). O livro didático de ciências no Brasil. 1ª. ed. Campinas: Komedi, 2006. 
12 Vasconcelos, CA et al. A oralidade nos livros didáticos de português: uma análise da língua materna através da prática pedagógica. In: III Encontro Sergipano de Educação Básica \& Vi Encontro de Professores de Língua. 2007, São Cristóvão. Anais. São Cristóvão: UFS/CODAP, 2007. p. 12- 23.

13 Krasilchik M. Prática de ensino em biologia. 4.ed. São Paulo: Editora USP, 2004.

14 Masetto MT. Didática: a aula como centro. 4.ed. São Paulo: FTD,1997.

15 Miras, M. Um ponto de partida para a aprendizagem de novos conteúdos: Os Conhecimentos prévios. In: ColL, César; Martín, Elena. O construtivismo na sala de aula. São Paulo: Ática, 2003.

16 Alarcon GG, Panitz CMN. Estudo comparativo da percepção ambiental de dois manguezais submetidos a diferentes condições ambientais e de ocupação urbana. In: II Simpósio Brasileiro de Etnobiologia e Etnoecologia, 1998. Resumos. São Carlos: Universidade Federal de São Carlos. p.13. 